\title{
Supply Chain Synergies in Post-merger Environments: The Case of the UK Food Industry
}

\author{
Ioannis Manikas \\ University of Greenwich, Department of Systems Management and Strategy, Old Royal Naval College, \\ SE10 9LS, London, UK, Email: mi37@gre.ac.uk (Corresponding Author) \\ Farzeen Jaswal \\ University of Greenwich, Department of Systems Management and Strategy, \\ Old Royal Naval College, SE10 9LS, London, UK
}

\begin{abstract}
Mergers are a complex phenomenon with a high failure rate inspite of the increased and more frequent mergers in companies today. This paper investigates the various factors that affect supply chain efficiency in post-merger environments and provides with a framework of requirements for a successful post-merger supply chain. The main aim is to assess the motives or initial expectations regarding value creation from mergers and analyse the post-merger effects of mergers on supply chain, also shedding some light on the major difficulties for the merging firms in achieving synergies regarding supply chains and managing key supply chain players in a way that maximum value can be extracted from the merger. Study is focused on the food industry in the UK. A questionnaire with 10 questions was sent out to supply chain managers of 600 people merged firms, representing approximately $40 \%$ of the overall mergers occurred in the UK Food and Beverages Industry between 2008 and 2012. 188 responses were received, representing $31 \%$ of the sample and $12 \%$ of the overall mergers between 2008 and 2012. It is found that mergers do not necessarily have a negative impact on the firms and their operational performance. In fact, this process can help in extracting many benefits by merging the two supply chains into one. Proper management, right strategy, trained workforce and good integration along the merger process can result in an efficient post-merger supply chain performance.
\end{abstract}

Keywords: food industry, mergers and acquisitions, post-merger efficiency, supply chain management

\section{INTRODUCTION}

In today's market, the ultimate mission of a firm is to make profits and improve shareholder wealth. Firms strive to grow by introducing new products and services to ensure internal growth (Green and Cromley, 1982); however, businesses seek to attain external growth by entering into Mergers (Ghosh and Das, 2003). Increased deregulation, globalisation and privatisation have been the main reasons for external growth strategies to gain spurt all over the world. It provided an important means to enter new markets, compete globally, broaden portfolios or to acquire new technology (Yadav and Kumar, 2005). Whether this speculative exercise becomes successful in achieving the basic objective or fails in doing so; undergoing this exercise has become the focus of various corporate discussions, both in the public as well as the academic world (e.g. Crandall and Winston, 2003). This Mergers 'wave ranged from small synergistic drop-ins to big deals altering the industry structure and competitiveness, covering many industries such as banking, oil and gas, Food and beverage, software, telecom and aviation.

\section{REVIEW OF DIFFERENT MERGER STRATEGIES}

Mergers can be used by an organisation when implementing any of the growth strategies -vertical integration, horizontal integration, diversification or going international. The main distinguishing feature of Mergers as a way to implement growth strategies is that the organisation is buying its expanded activities and operations (Coulter, 2005). Thus, avoiding Mergers in today's time is like missing an opportunity. According to Harrison (1987), if the decision to grow by Mergers is made, the potential acquirer must be very sure that the stipulated aims are unattainable by alternative measures. Fauli-Oller (1997) and Hennessy (2000) show that in a merger which is done with an anticompetitive intent, profit derived from Mergers is usually the gains from cost reduction or other synergy gains.

\subsection{Objective to Become Leaner}

The most common strategy used by merging firms is to create cost effective, leaner operations base from the combined companies in the same industry thus achieving operational synergy. Inefficient plants can be closed or distribution activities partly combined and downsized (when nearby centres serve some of the same geographic areas), or sale force and marketing activities combined and downsized (when each company has salespeople calling on the same customer). Thus, supply chain cost synergy can be achieved from the combined companies because of buying in greater volume from common suppliers and from closer collaboration with supply chain partners. Likewise, administrative activities can be downsized and squeezed resulting in cost savings. For example, the merger forming DaimlerChrysler started with the objective to use the high capacity that was more than needed. The two companies Daimler-Benz and Chrysler believed that closing some inefficient plants and realigning the activities by combining supply chain activities, product design and administration would result in significant cost savings. A large number of Mergers are done with the intent to replace small high-cost 
companies to one leaner unit. It also helps in logistics management where through Mergers, large operators have come up to gain from economies of scale in ship sizes and network organization from origin to destination (Marchese et al., 1998).

\subsection{Objective to Expand Geographic Coverage}

Mergers provide a route to enter new markets in order to enhance firms value (Shelton, 1988). One of the best ways to expand a business geographically is to acquire a business in the desired location. This also helps in dealing with the geographic overlap with a side benefit of reducing costs by eliminating duplication of activities. Many food companies like Nestle, Kraft, Unilever and Procter \& Gamble have chosen this route to expand their business in different parts of the world. However, in such mergers, it is important that the goals of both the firms should be in line with each other (Das and Teng, 2000) for better synergy (Eun and Resnick, 2004) and desired success (Srilata et al., 2003). Internationalisation is also one of the important strategies that firms are adopting in today's market to spread its operations in foreign countries. Domestic Mergers are easier to execute because of the familiarisation of both the involved companies, the laws, procedures and other such factors however in case of international Mergers there are various complexities involved (Hitt et al., 2005). Firms opting for this route save themselves from time consumed to enter and set up a business in the foreign country. Eun et al. (1996) conducted a study in the US which shows that cross border Mergers create immense wealth for acquiring shareholders. For a company to consider overseas operation through mergers, a reason may be to increase the sales potential of the firm or improved production efficiency e.g. low cost labour (Johnson, 1999) while double taxation and anti-trust issues make such transactions unattractive (Gaughan, 2007). However, multinational Mergers is highly risky due to fluctuating exchange rates, political risks and unclear distinction between parent and subsidiary (or associate) firm's cashflows which makes it less attractive (Johnson, 1999). Brewer et al. (2001) studied international mergers and concluded that many international mergers have been unsuccessful because it is difficult to maintain globalised supply chains and manage logistics, where many serious issues on competitive effects and mismanagement of supply chains during mergers are raised.

\subsection{Objective of Diversifying}

Jose et al. (1986) defined diversification as a process of entering different industries with a view to improve financial performance and enhance shareholder value. This helps in reducing detrimental effects from industry specific risks. Firms prefer to merge with a similar instead of experimenting into a new line of business of which it lacks experience and know-how (Hitt et al., 2005). Wang and Reuer (2006) asserted that shareholders tend to reduce their risk through Mergers, where they diversify their business portfolio in order to mitigate industry-associated risks. In contrast, Amihud and Lev (1981) diversification does not create values to shareholders and instead it is done by managers to incentivise by diversifying their employment risk.

\section{MERGERS IN THE UK FOOD INDUSTRY}

In 2000, Food Mergers in 18 out of the 27 Food or Food-related categories was reported by the Food Institute (Harris et al., 2002). During 2010, the Food Institute found 322 mergers, which is an increase of $22 \%$ from year 2009 (Fusaro, 2011). There were a total 316 mergers in 2012 showing a fall of about 17\% from 2011 however, some analysts believe that this figure will increase in year 2013, while others think the opposite. Anyhow, the number of annual mergers indicates the significance and popularity of mergers transactions in UK's FOOD industry. Also, since 2012, UK Food manufacturing industry has become very attractive for overseas buyers and firms are being acquired by e.g. German and Chinese buyers, and it is believed that the trend of such cross-border mergers will continue in 2013 (Mclean, 2013 cited by Harwood, 2013). A detailed number of mergers in the last five years as researched by the Food institute (cited by Food processing, 2012) are shown as follows in separate categories;

Table 1 Mergers and Acquisitions in the UK Food Industry between 2008 and 2012 (source: Food processing, 2012)

\begin{tabular}{|l|ccccc|}
\hline & $\mathbf{2 0 1 2}$ & $\mathbf{2 0 1 1}$ & $\mathbf{2 0 1 0}$ & $\mathbf{2 0 0 9}$ & $\mathbf{2 0 0 8}$ \\
\cline { 2 - 6 } Food processors & 79 & 83 & 67 & 58 & 140 \\
Brewers, Wineries & 12 & 11 & 5 & 6 & 22 \\
Dairy & 8 & 6 & 5 & 7 & 7 \\
Fruit \& Vegetables & 32 & 12 & 14 & 4 & 10 \\
Meat & 2 & 9 & 4 & 3 & 12 \\
Snack food & 18 & 7 & 6 & 2 & 8 \\
Others & 165 & 242 & 221 & 184 & 93 \\
Total & $\mathbf{3 1 6}$ & $\mathbf{3 7 0}$ & $\mathbf{3 2 2}$ & $\mathbf{2 6 4}$ & $\mathbf{2 9 2}$ \\
\hline
\end{tabular}

There are many reasons for the increase in mergers in Food Manufacturing businesses. Firms see it as a way to help in closing the less efficient processors and broadening the product lines that helps in increased market share. It also helps in efficient Food retailing with more information sharing between the companies. food businesses account for 
the largest portion in UK economy representing over $15 \%$ of manufacturing turnover and employment and it contributes to more than $£ 68$ billion, out of which $10 \%$ ( $£ 6.8$ billion) is comprised of dairy industry (Research Food centre, 2013). During 2013, UK food manufacturers announced about 2,600 employees. However, considering the significance, it is also important to note that if a food business fails, a large number of employees get affected. For example, during 2012, many companies in the UK food sector failed, which affected more than 48,000 employees (Thomas, 2013).

It has been four years since the consumer recession occurred and there is no indication to see it ending anytime soon. Consumers are more focused on gaining value for money that has changed the buying habits of customers. Firms face constant pressures to rapidly respond with changing demands and this requires close coordination between the firms. Vertical mergers have been found as a solution to this problem where firms along the supply chain work closely to improve their responsiveness. It also helps in reducing the transaction costs associated with the market exchange (Perry, 1989). Reduction of risks, increased capability to innovate, improved information exchange and a better market position are a few benefits that attract the attention of the top management of a firm while deciding a merger deal.

\section{RESEARCH OBJECTIVES}

This paper examines the relationship between the performance of supply chain, overall operational performance and impacts on the overall performance after the merger. The researchers aim to define the important features of the motives or initial expectations regarding value creation from mergers and analyse the post-merger effects of mergers on supply chain, also shedding some light on the major difficulties for the merging firms in achieving synergies regarding supply chains and managing key supply chain players in a way that maximum value can be extracted from the merged firms business. The preeminent goal of this research is to study and find out the impacts of mergers on supply chains.

\section{RESEARCH DESIGN}

This research uses a systematic approach process to evaluate the effects of mergers on supply chain and its direct relation with success of the mergers process. A questionnaire with 10 questions was sent out to supply chain managers of 600 merged firms (via SurveyMonkey), representing approximately $40 \%$ of the overall mergers occurred in the UK Food and Beverages Industry between 2008 and 2012. 188 responses were received, representing $31 \%$ of the sample and $12 \%$ of the overall Mergers between 2008 and 2012 (Table 2).

Table 2 Survey Details

\begin{tabular}{|c|c|c|}
\hline & No. of Participants & Participants \% \\
\hline \multicolumn{3}{|c|}{ Area of business } \\
\hline Manufacturing & 102 & $49 \%$ \\
\hline Retail & 58 & $36 \%$ \\
\hline Distribution & 28 & $15 \%$ \\
\hline Total & 188 & $100 \%$ \\
\hline \multicolumn{3}{|c|}{ Size of Company } \\
\hline Small & 16 & $9 \%$ \\
\hline Medium & 76 & $40 \%$ \\
\hline Large & 96 & $51 \%$ \\
\hline Total & 188 & $100 \%$ \\
\hline \multicolumn{3}{|c|}{ Age of Company } \\
\hline $1-10$ years & 12 & $6 \%$ \\
\hline $10-20$ years & 36 & $19 \%$ \\
\hline $20-30$ years & 92 & $49 \%$ \\
\hline $30+$ years & 48 & $26 \%$ \\
\hline Total & 188 & $100 \%$ \\
\hline \multicolumn{3}{|c|}{ Average Annual Turnover } \\
\hline$£$ 3-4 million & 8 & $4 \%$ \\
\hline$£ 4-5$ million & 20 & $11 \%$ \\
\hline$£ 6-8$ million & 52 & $28 \%$ \\
\hline
\end{tabular}


Table 2 Survey Details (Con't)

\begin{tabular}{lcc}
\hline & No. of Participants & Participants \% \\
\hline$£ 8+$ million & 108 & $57 \%$ \\
Total & 188 & $100 \%$ \\
\hline
\end{tabular}

\section{RESEARCH FINDINGS}

The researchers evaluate the impacts of mergers on supply chain with specific attention on the expectation gap between the motives behind a merger agreement compared to the actual results derived later. This explains that there are various non-financial factors which hinder the success of a merger.

\subsection{Control Factors}

$49 \%$ of the survey respondents belonged to manufacturing business, $36 \%$ to retail business and $15 \%$ to distribution business. The majority of respondents represented the manufacturing sector. Most of the survey respondents belonged to medium or large sized companies which started about 20 to 30 years ago and with more than 1, 000 employees.

Even though most mergers are carefully designed, they are extremely difficult to be managed and face many challenges. Despite of the expected synergy values, most of the Mergers fail to accomplish the beneficial goals and instead result into a failure. Merger failure has various reasons which, predominantly, occur due to unattainability of supply chain integration. Supply chain experts believe synergies are not achieved in $50-70 \%$ of merger cases in the UK. About 90\% successful Mergers do not fully accomplish the strategic objectives. Productivity and financial performance falls by $50 \%$ while people's management also becomes a problem soon after the merger (Table 3).

Table 3 Merging Challenges for Supply Chain Integration

\begin{tabular}{|c|c|c|c|c|c|}
\hline \multicolumn{6}{|c|}{$\begin{array}{l}\text { What do you think is the biggest challenge during achieving supply chain integration when merging operations (\% } \\
\text { percentage)? }\end{array}$} \\
\hline & Very Easy & Easy & $\begin{array}{l}\text { Neither easy } \\
\text { nor difficult }\end{array}$ & Difficult & Very difficult \\
\hline $\begin{array}{l}\text { Merging supply chain partners to help } \\
\text { business maintain key players }\end{array}$ & 0 & 2 & 17 & 33.5 & 47.5 \\
\hline Managing inventory for changing demand & 2 & 6.4 & 19.2 & 52.7 & 19.7 \\
\hline Merging top level management & 0 & 4.3 & 23.4 & 38.3 & 34 \\
\hline Merging cultures & 0 & 0 & 10.6 & 32.4 & 57 \\
\hline Managing people (redundancies) & 0 & 8.5 & 32.4 & 23.4 & 35.7 \\
\hline
\end{tabular}

Large Food companies usually choose to expand through mergers to gain greater market strength. However, since 2010, the number of food mergers has reduced due to post-merger failures. Where management believes that mismanagement of people is the most important factor leading to failure, it is believed that the failure is predominantly due to failure in managing supply chains. Failure in managing Food supply chains is not a small issue. It can result in delayed supply from suppliers, slow manufacturing, delayed supply of Food products to market affecting their freshness, poor service to customers by providing near to expiry Food products, high security and compliance risks as well as missing good opportunities in the market. Thus, the primary focus should be on the external rather than internal issues i.e. on customers rather than employees.

The Food supply chain should be managed in such a way that it best suits the on-going provision of services to customers with on-time orders and delivery of goods. Supply chain can be considered as best managed if it does not lead to ambiguity in handling information from both the supply chains joined as one and all customers are dealt with in the right time. Even in small and medium sized companies where integration is not an as big issue as in large Food firms, still it is found that the success rate is not more than $50 \% .81 \%$ of the survey respondents believe that managing supply chain is the biggest challenge during a Food Industry merger.

\subsection{Mergers and Inorganic Growth}

Analysing the results it was found that a $28 \%$ of respondents agree that mergers are majorly done for inorganic growth of the business. Supply chain managers believe that the trend towards Food Mergers in the UK will increase in the next coming years with intent to grow the business. Not only inorganic growth, but companies have become increasingly concerned about organic growth as well. $25 \%$ of the respondents believe that the major benefit extracted from mergers is the resulting strong collaboration. It is important for achieving flexibility, lower response time 
and better delivery performance which is very important for Food industry for dealing with the perishability constraint. Tight collaboration is also rated as a highly important factor in the Food business for ensuring shorter lead times and better responsiveness. There are cases where manufacturers are found to be unaware about the best practices or unable to execute them, giving rise to compliance issues.

\subsection{Greening the Supply Chain}

From the survey it was found that a $62 \%$ of respondents strongly agree to the fact that economies of scale are better achieved through mergers while increased capabilities (57\%) and geographical dispersion (49\%) are also big achievements that instigate the desire to merge with another business. Another important worth discussing finding during the research was that only $25 \%$ agree that mergers can help in improving green friendliness whereas $57 \%$ disagree and $17 \%$ were neutral on the idea that green friendliness is also a motive behind merging with another entity. It was also found that companies usually do not merge majorly with this intent. However, greening the supply chain is considered as a new model for enterprises to achieve profit and market share objectives (Tundys et al. 2015), thus they might use it as a green-washing technique to deceptively capture consumers' attention but most of the businesses merge with intent for financial gains whether through synergistic gains but the focus is always on the financial and operating performance rather than environmental, social or consumer welfare. Food manufacturers are dependent on their supply chains. Supply chains are constantly changing and one of the main reasons for this is the changing trends in the Food sector. People are moving towards more healthy organic Food with less or no artificial ingredients and this is being mentioned on the products' packaging as well. As per consumer demands, not just Food but also the packaging material should not be a threat to the environment and should be recyclable.

\subsection{Operational Effectiveness and Input Prices}

Operational effectiveness will improve further but the prices of the inputs can be a threat. This includes, for example, the surging water shortage and increasing prices, plastic bottles/packaging cost and fluctuating petrol prices affect the input costs. Thus, cost reduction initiatives will also take most of the attention of the Food businesses. However, the big concern is to use the cash sensibly and at the right place at the right time. Hence both capital and revenue expenditures should be effectively managed.

\subsection{Inventory Management}

Inventories are reduced and Food companies are moving to less or no inventory conditions which have increased dependence on suppliers and the relationship with them. This requires efficient supply chains with good communication. $72 \%$ survey respondents believe that managing inventory is a difficult task in a Food merger. Inspite of collaboration, lack of adequate information systems (such as ERP and CRM) greatly hinders communication between the supply chain partners, thus it requires increased investment and attention. Food companies are trying to become more efficient in communication and therefore are investing or planning to invest in technologies which would help in good communication. Use of technologies like cloud computing (and data analytics) will help in improving responsiveness in the future showing considerable reduction in lead times. But it is a complex technology which is very costly and would require spending on training employees as well. In this way customer loyalty can also be achieved when customer demand is met timely.

\subsection{Demand Fluctuations}

$28 \%$ respondents believe that the failure to manage supply chains is not majorly due to demand fluctuations; however, $66 \%$ believe that demand fluctuations only moderately affect the operational performance. Working capital optimisation across the supply chain networks is therefore important. For example, inventory optimisation requires selecting a right strategy to ensure the supply chains become leaner and agility can be achieved. Thus, supply chains should be flexible enough to deal with the demand rise and fall. The vulnerability of these risks is even higher for manufacturer, retailers and distributors in Food industry due to short life cycle and essentiality of lower delivery time due to perishable products. These companies usually make profit from sale of high volumes and low margins. In such conditions, communication is an essential element and postmerger, it is feared that a potential disaster can occur.

\subsection{Planning Merger and Gaining Integration}

Companies excessively plan before merger. The merger supply chain integration should not be delayed and dealt with within the first six months. This is the time when supply chain goals are being set. Regarding timing of supply chain integration, it should not take more than two years to attain integration between the supply chains of the merged firms otherwise it will be impossible to achieve success in the merger deal. In this way, effective integration can help in making the company more adaptable to changes in trends and customer demands. Supply chain re-engineering is increasingly used to identify the problems and manage supply chains. This can be either planned pre-merger or thought about post-merger according to the conditions then. $57 \%$ survey participants chose to have a pre-planned strategy devised while planning a merger in order to have lesser risk of failure in achieving supply chain synergy. $38 \%$ of respondents believe that post-merger conditions can better help in devising a strategy.

\subsection{Horizontal or Vertical Mergers}

$72 \%$ of the participants disagree with the fact that horizontal mergers are more successful than vertical mergers in the Food industry, further stating that vertical mergers can thus be more successful and give longer-lasting benefits. Vertical integration has become an integral part of Food businesses where firms have become more customer-driven. Thus, specialisation is not considered an as big issue as the competitive advantage through improved efficient supply chain performance is considered. Same function businesses 
do not help in extracting as many advantages as vertical Mergers or Mergers along the supply chain. Vertical mergers help in creating a closer and efficient network with supply chain partners that has become a necessity for businesses. Benefits gained from horizontal mergers can be exercised through a good experienced workforce and more investment as well. However, economies of scale are a major benefit from horizontal Mergers. Thus, it is not genuine to determine which of the types is more fruitful but it all depends on the requirement of the business at the time of merger whether it is looking for economies of scale gains or efficient operations gain through mergers.

\subsection{Strategic Fit and Cultural Synergy}

During the survey, it was found that up to $89 \%$ of the participants believe that merging different cultures is the most difficult job during a merger. This, as well, has many reasons; strategic fit is one of the main requirements for successful mergers but it is extremely difficult to achieve. It is obvious that the two companies operating separately have differing aims and objectives and they exercise different strategies to accomplish them. Hence, the conflict may result in a poor strategic fit and ultimately synergy values can be very elusive. Cultural differences and culture shock are a significant reason for failure. Risk orientation and cost consciousness often quite differ between the merged businesses. Inadequacy of due diligence exercise is also proved with the failure. Supply chain integration is hard to be managed since effective supply chain management requires careful consideration of multiple tiers of partners, especially with respect to sustainability issues (Mocan et al, 2015). Often different supply chain re-engineering techniques are used to make supply chains more efficient. A high level of planning and design is required to ensure supply chain network optimisation otherwise the implementation fails. However, it is also found that the weaknesses in gaining integration and synergies with the acquired company are not always evident. Cultural, social and managerial problems may also become visible later. Thus, the envisioned synergy becomes ambiguous. Maybe because of skills not being transferred or key managers leaving the company, the anticipated success turns to be a failure. Hence, even if the staff was experienced, the success might not be retrieved. There should be a strategy for creating a pattern of integration to achieve synergy and this strategy can be further developed according to the conditions found later. Many top-level managers leave their job after merger. This becomes a major issue if the major source of competitive advantage of the company is its managers. The managers of the two companies may be following different values, ethics and beliefs in the product manufacturing, quality of product and service offered and these should reconcile.

\subsection{Talent Management}

$60 \%$ of the respondents believe that managing people and redundancies is a very difficult job and this has also led to increased growth of talent management in the Food Mergers. It is also found that almost $72 \%$ respondents believe that merging the top-level management is very difficult in a Food business. Lack of qualified workforce is also a big issue due to which training of employees in Food sector has also picked attention and focus of the top managements. Some firms also fear to give the autonomy to see the supply chain in the hands of employees thus less than required workforce is given a supply chain job. Manufacturers and retailers are actively planning to spend about $1-3 \%$ of the savings on training their employees.

\section{CONCLUSIONS AND RECOMMENDATIONS}

Mergers are a complex phenomenon with a high failure rate inspite of the increased and more frequent Mergers in companies today. There are times where more than one merger is being managed. Despite their benefits and popularity, about half of the Mergers fail to achieve the desired strategic or financial objectives. This can be due to various reasons that were analysed during in the research. Improper due diligence, imprecise pricing, a wrong objective behind the merger, a wrong strategy to achieve the motive, wrong acquirer/acquire or wrong timing (Marks, 1997). Where Mergers are done to increase the chances of continued sustainability, the researcher argued that an important reason contributing to the high failure rate lies in neglecting the value of achieving integration. A careful planning should be done before the merger and the whole merger process should be done accordingly. It is also found that changes can be brought according to the post-merger conditions but a basic planned strategy should be prepared before the merger. Cultural differences, doubling of jobs and redundancies should be carefully managed with a premerger plan. Due diligence services should be taken from a good reputed advisory firm which has experience of merger in the respective industry in order to assure that the due diligence report is effective enough to find a strategic fit between the two companies which are planning to merge and should ensure success of the merger. Later, it is difficult to find out whether the deal failed due to an improper due diligence or an ineffective management.

Nowadays, in the Food industry, the form of Mergers usually undergone is vertical merger to improve supply chain network. The first point of concern is the basic motive and the performance measures that are decided to be used as the indicators for measuring good or bad performance. As the basic motive of most of the businesses found through the survey is to grow inorganically while managing supply chains in such a way that tighter collaboration can be reached; managers should aim to effectively manage supply chain in order to build a closer communication network with the partners (suppliers). Appropriate performance measures should be used to make sure that performance is measured accurately. Moreover, integration must be achieved within a span of 24 to 26 months. Otherwise, it will become impossible to extract benefits after all the costs/expenses incurred. Employees should be given autonomy to work on supply chains and they should also be trained. Thus, talent management has also become an important aspect of supply chain management of mergers especially in Food industry. The perishability of the Food products also requires storing less or no inventory to provide fresh products to customers, who have become increasingly aware and concerned about the health concerns. Storing costs can also be save in this way Thus with, efficient integration, tighter collaboration, 
good communication of information along the supply chain partners, trained workforce and effective merging of top level management and the two cultures can result in a successful merger.

When it comes to the main research questions, the researchers studied the different motives behind Mergers and investigated to find a reason, which can result in success of the deal (Figure 1). The results show that it is important to have an appropriate objective to pursue a merger.

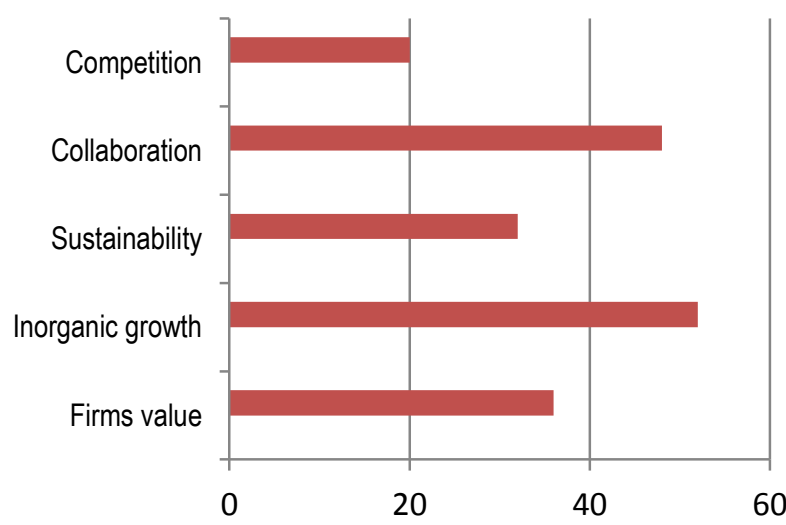

Figure 1 Overview of Motives for Mergers in the UK Food Industry

Economies of scale has been a main reason for Mergers in the Food industry which can result in achieving increased revenues and lower costs while manufacturing, delivering Food products while reducing losses. Thus, Food firms usually aim to achieve a leaner supply chain. Producing and providing green-friendly products has also gained importance in Food industry with more firms becoming concerned about becoming health and environmentally conscious and aware. Population increase and resulting demand rises are already forecasted and firms are aiming to gain the most of the market share to benefit by adding more customers to their network. The role of internet and information technologies cannot be ignored in this respect. While in Food industry, more efficient and responsive system of communication is required, firms are aiming to invest more in this area. Supply chain reengineering has also gained spurt in the past few years. There is a greater scope to redesign the supply chains in such a way that expenses are downsized and profits can be improved. Thus, supply chain engineering can help in creating a competitive advantage but this may require efforts from all supply chain partners.

As described earlier, there are numerous reasons for failure of a merger. However, it is difficult to identify exactly which reason resulted in failure of the deal. This requires further research and study in measuring the synergistic gains that should be easily identifiable rather than imaginary. Study is also required to assess the best timing for undergoing a merger. Subsequently, what the firms should do to ensure that the merger process is conducted well also requires further study. Furthermore, with the advent of ethical issues in the Food industry and the rising health concerns, it is also found that supply chains are so complex that it is difficult to identify where the main problem lies. This area requires a lot of research to analyse the problems and ways to solve them. Moreover, ways on seizing new customers and retaining them in a Food business will also require more study.

\section{REFERENCES}

Amihud, Y., and Lev, B. (1981). Risk reduction as a managerial motive for conglomerate Mergers. Bell Journal of Economics 12 (2), pp. 605-617.

Brewer, A., M., Button, K., J., and Hensher, D.A. (2001), Handbooks in transport Vol 2: Handbook of Logistics and supply chain management, Oxford, UK, Elsevier Science Ltd.

Coulter, M. (2005), Strategic Management: in action, 3rd ed. New Jersey, Pearson Prentice Hall.

Crandall, R. W., and Clifford, W. (2003). Does Antitrust Policy Improve Consumer Welfare? Assessing the Evidence. Journal of Economic Perspectives 17. 326.

Das, T. K., and Teng, B. S. (2000). A resource-based view of strategic alliances. Journal of Management 26 (1), pp. 31-61.

Eun, A., and Resnick, D. (2004), International Financial Management, McGraw-Hill, 3rd ed, pp. 1-30.

Eun, S.C., Kolodny, R., and Scheraga, C. (1996). Crossborder acquisitions and shareholder wealth: Tests of the synergy and internalization hypotheses. Journal of Banking \& Finance 20, pp.1559-1582.

FAO (2009), 2050: A third more mouths to feed. Food production will have to increase by 70 percent, FAO convenes high-level expert forum.

Food Processing (2012), Mergers and Acquisitions Report 2012: Despite Uncertain Times, Asset Swapping Continues.

Fusaro, D. (2011), Mergers and acquisition activity returning to pre-2008 levels. Food Processing.

Gaughan, P. A. (2007), Mergers, Acquisitions and corporate restructurings, 4th ed. New Jersey, John Wiley \& Sons.

Ghosh, A., and Das, B. (2003). Mergers and takeovers. The Management Accountant 38 (7), pp. 543-545.

Green, B. M., and Cromley, G. R. (1982). The Horizontal Merger: Its motives and Spatial Employment Impacts. Economic Geography 58 (4), pp. 358-370.

Hennessy, D. (2000). Cournot Oligopoly conditions under which any horizontal merger is profitable. Review of Industrial Organisation 17(3), pp. 277-284.

Hitt, M., Ireland, R. and Hoskisson, R. (2005), Strategic Management Competitiveness and globalisation (concepts), 6th ed, Thomson- South-western, Mason, $\mathrm{OH}$.

Hitt, M.A. (2001), Mergers and Acquisitions: A Guide to Creating Value for Stakeholders, New York, Oxford University Press.

Johnson, H. J. (1999), Mergers and acquisitions: a framework for the right executive decision, London, Pearson Education Limited.

Jose, M.L., Nichols, L.M., and Stevens, J.L. (1986). Contributions of diversification, promotion and R\&D to the value of multiproduct firms: A Tobin's Q approach. Financial Management 15, pp. 33-42.

Marchese, U., Musso, E., and Ferrari C. (1998), The role for ports in intermodal transport and global competition: 
a survey of Italian container terminals. World Transport Research: Selected Proceedings of the 8th World Conference on Transport Research, pp.141154.

Mclean, A. (2013) Overseas deals to drive Food and manufacturing Mergers and acquisitions[Online]. Available in: www.foodmanufacture.co.uk

Mocan, M. L., Turi, A., and Goncalves, G. (2015). Can an Underachiever Become Competitive? The Case of the Romanian Food Industry. Operations and Supply Chain Management, 8 (2), pp. 101 - 110.

Perry, M. (1989), Vertical integration: Determinants and effects, in: Schmalensee, R., and Willig, R.D. (eds.) Handbook of Industrial Organisation, North Holland. New York, (1), pp. 183-255.

Shelton, L. M. (1988). Strategic business fits and corporate acquisition: empirical evidence. Strategic Management Journal 9 (3), pp. 279-287.
Srilata, Z., Schomaker, M., and Genc, M. (2003). Identity Versus culture in Mergers of equals: European Management Journal 21 (2), pp. 185-191.

Thomas D., 2013. UK retailer distress rises and set to get worse. The Financial Times.

Tundys, B., Rzeczycki, A. (2015). Construction of Green Supply Chain for Organic Products. Operations and Supply Chain Management, 8 (1), pp. 37 - 47.

Wang, H., and Reuer J.J. (2006). Risk reductions through acquisitions: The roles of firm specific investments and agency hazards. Advances in Mergers and Acquisitions 5, pp. 25-49.

Yadav, A.K., and Kumar, B. R. (2005). Role of Organization Culture in Mergers and Acquisitions. SCMS Journal of Management 2 (3), pp. 51-63.

Dr. Ioannis Manikas is a Principal Lecturer of Logistics and Supply Chain Management in the Department of Systems Management and Strategy at the University of Greenwich. Dr Manikas holds a BSc in Agriculture and Food Science from the Aristotle University of Thessaloniki and an MSc from Cranfield University, United Kingdom. He holds a PhD from the Department of Agricultural Economics of the School of Agriculture in Aristotle University of Thessaloniki and he has conducted research for projects regarding supply chain modelling, development of IT solutions for agrifood supply chain management and traceability both in Greece and the UK.

Farzeen Jaswal is Farzeen Jaswal is an MBA student at the Faculty of Business of the University of Greenwich, London. 